\title{
FREDERICO MORAIS: A CRISE DA VANGUARDA CONSTRUTIVA NO BRASIL (1960-70)
}

\begin{abstract}
Marcelo Mari
FAV-UFG

Resumo

Quando Frederico Morais organizou os eventos no Aterro do Flamengo a proposta já era, como em Hélio Oiticica, de eliminar a distância entre a arte contemporânea, seu significado social e as massas urbanas. Aproximar as pessoas da arte, aproximar a arte da vida, esse foi um dos objetivos dos eventos que marcaram a démarche das neovanguardas dos anos de 1960 e de 1970. No caso específico das artes, o objeto - como categoria artística - tinha ganhado importância no processo de comunicação das linguagens visuais e tornou-se elemento chave para a realização da exposição Objeto e Participação no Palácio das Artes em 17 de abril de 1970. Juntamente com a exposição, Morais pensou na realização de manifestações artísticas (arte vivencial, conceitual ou efêmera e etc.) no espaço do Parque Municipal de Belo Horizonte, conhecida como Do corpo à terra, entre os dias 17 e 21 de abril de 1970.

Palavras-chave

Frederico Morais, Do corpo à terra, Golpe Militar.
\end{abstract}

\section{Abstract}

When Frederico Morais organized the events in Flamengo t embankment, the proposal was already, like Helio Oiticica, to eliminate the gap between contemporary art, its social meaning and the urban masses. Approaching people of art, the art of life, was one of the goals of the events that marked the demarche of neovanguards the years 1960 and 1970. In the specific case of the arts, the object as artistic category - had gained importance in the communication of visual languages and became a key element to the exhibition Object and Participation in the Palace of Arts on April 17, 1970. Along with the exhibition, Morais thought performing art forms (art experiential, conceptual or ephemeral and so on.) within the Municipal Park of Belo Horizonte, known as Do corpo à terra, between 17 and 21 April 1970.

Key-words

Frederico Morais, from body to the earth, Military coup 
A crise institucional imposta pelo golpe militar de 1964 pôs fim derradeiro às vanguardas construtivas e ao estabelecimento de um novo estágio de influências e de alternativas possíveis da arte brasileira, processado como manifestação consequente de uma crise ética, política e social que assolou o País. Se a tendência construtiva da arte brasileira fez parte do período desenvolvimentista dos anos de 1950 e dramatizou sua crise, a partir da década seguinte com o Golpe Militar e os anos que o sucederam, as sendas artísticas brasileiras estiveram ligadas ao movimento generalizado internacionalmente de nova figuração, de pop arte ou de antiartes e tiveram entre suas manifestações epígonas a arte conceitual que acompanhou todo processo de recrudescimento da repressão política nos anos finais de 1960 e durante a década seguinte de 1970.

O terror empregado pelos militares, que se implantou com o estabelecimento do Ato Institucional de Número 5, (AI-5), a partir de 1968, deixou em evidência a pálida consciência da crise do projeto vanguardista no Brasil. Desse período, são exemplares a produção artística da Nova Figuração de Gerchman, de uma mistura de pop art \& de arte Povera aquilatadas por Flávio Império e por Sérgio Ferro, e logo em seguida, no início dos anos de 1970, as intervenções de um Arthur Barrio e de um Cildo Meireles. Tratava-se do fim da arte que fazia da apreensão perceptiva a base de reformulação da dimensão estética da realidade para a compreensão da arte como algo para além da ênfase pura e simplesmente no dado visual.

Essa arte que tomou o conceito como elemento poético principal teve como um de seus estimuladores o jovem crítico Frederico Morais concebeu e organizou o evento Do corpo à terra em Belo Horizonte no mês de abril de 1970. Em um longo depoimento posterior, Morais dizia:

"Na história da arte brasileira, é referido apenas com o nome Do Corpo à Terra. Mas, na realidade, foram dois eventos simultâneos e integrados, a mostra Objeto e Participação, inaugurada no Palácio das Artes, em 17 de abril de 1970, e a manifestação Do Corpo à Terra, que se Desenvolveu no Parque Municipal de Belo Horizonte, entre 17 e 21 de abril do mesmo ano, promovidos pela Hidrominas - empresa de turismo do Estado de Minas Gerais". (MORAIS, 2004, p. 115-116).

Nos anos seguintes, Morais iria produzir um ensaio intitulado $A$ crise da vanguarda no Brasil em que ele fazia um balanço sobre as principais iniciativas 
produzidas na arte brasileira dos anos de abertura democrática ao fim do Estado Novo até os anos iniciais e fatídicos após o Ato Institucional número 05. Nesse ensaio, Morais define a atividade de vanguarda como "atualização permanente", isto é, fazia sentido falar ainda em arte de vanguarda no Brasil devido ao caráter transgressivo de suas propostas e ao entendimento de que a arte que se produzia naquele momento estava à frente das questões estéticas de seu tempo (tal como as vanguardas europeias tinham também cumprido esse papel anteriormente). Esse impulso tardio de afirmação do caráter vanguardista da arte brasileira tomou conta de gerações de intelectuais e de artistas e foi resultado de um processo de ruptura com o modernismo da primeira metade do século $X X$.

O fim dos 'ismos', nos anos de 1970, decretou a obsolescência do conceito de vanguarda muito ligado ainda à questão da inovação formal. $\mathrm{Na}$ definição de Frederico Morais, em A crise da vanguarda brasileira, o registro sobre a arte de vanguarda é outro: "A arte como ação e engajamento. $O$ artista de vanguarda não se restringe a produzir obras. Ele luta por impor suas ideias, que não se esgotam, evidentemente, no campo estético." (MORAIS, 1975, p. 69). Essa definição deixa entrever pelo menos duas coisas: em primeiro lugar, o fato de Morais estar envolvido com a produção de arte conceitual no Brasil e, em segundo lugar, que a arte produzida - naquele momento - já não se identificava com a experiência, sobretudo estética (baseada na visualidade) da vanguarda construtiva no Brasil.

Nesse sentido, o termo vanguarda está posto para descrição tanto da vanguarda construtiva como da arte conceitual do final dos anos de 1960 e da década seguinte. Morais levanta os princípios que nortearam a promoção de vanguardas artísticas brasileiras e como elas estiveram envolvidas com a construção histórica e social de um novo projeto de Brasil, suas conquistas e derrotas. Daí é possível identificar uma vanguarda proativa (construtiva) e outra retroativa (conceitual) na arte brasileira.

Depois de explicar o projeto da vanguarda artística brasileira, Morais aponta sua crise por causa das circunstâncias políticas do País e, por conseguinte, pela entrada do mercado como baliza de reordenamento da produção artística brasileira nos anos de 1970 em diante. Há pelo menos dois sentidos atribuídos por Morais ao termo crise, a saber: por um lado, o termo refere-se ao processo de inviabilização do projeto moderno brasileiro com a crise do desenvolvimentismo que levou juntamente consigo os anseios depositados na potencialidade transformadora da arte moderna 
autônoma de cepa construtiva; por outro, a crise da vanguarda brasileira faz referência à falta cada vez mais generalizada de liberdade para a produção artística e à desestruturação do sistema das artes plásticas no Brasil (exílio da crítica, perseguição dos artistas, descrédito nas novas ocupações das instituições e dos museus, etc.) em detrimento do incentivo das atividades ligadas ao principiante mercado de arte local.

Esses dois sentidos completam-se na verificação tanto da exaustão dos processos políticos e artísticos envolvidos na abertura de perspectivas e de potencialidades transformadoras da realidade como no processo de autocrítica, vivenciada por intelectuais e por artistas ligados ao mundo das artes, sobre a importância especial da arte na transformação da realidade.

Para Morais (1975), a crise da vanguarda brasileira dava-se com o processo de interdição do funcionamento e da normalização do sistema das artes local (crítica, artistas, instituições) resultado dos anos de repressão sistemática assistidos no Brasil em que artistas, intelectuais e militantes foram atacados, reprimidos, mortos ou foram para o exílio forçado. O que ocorreu a partir daí foi uma mutação profunda do significado atribuído ao sistema das artes e ao seu funcionamento; se antes do Golpe Militar, a constituição de um público interessado e a consolidação da crítica de arte tinham fabricado as bases para ampliação de um ambiente estético particular no Brasil que contava também com o apoio e estabelecimento de suas instituições modernas, a partir da crise do projeto moderno no Brasil, (cujo precedente poderia ser enunciado pelo apoio fundamental dos Estados Unidos para o estabelecimento aqui dos museus de arte moderna e cuja situação mais recente indicava o uso instrumental ou a incorporação das mais ousadas invenções da arquitetura funcionalista pelo regime militar), tanto artistas como arquitetos e intelectuais engendraram ou promoveram uma produção artística baseada na nova assimilação do moderno.

Em seu ensaio, Morais apontava a desrealização e o fim inconcluso da tendência construtiva na arte brasileira, fazendo relação entre o ideário artístico e o social. Embora com fim inconclusivo, a tendência construtiva brasileira apresentavase tanto como uma projeção utópica quanto como uma tentativa frustrada, pois ilusória aos olhos do crítico. A referência ao discurso inaugural de Juscelino Kubistchek servia para enfatizar o peso que se depositou na construção de Brasília como símbolo de uma nova época: 
"Vejo, em nosso encontro, um símbolo. Nele reluz uma significação extraordinária. Sugere, ou antes, afirma, e veementemente, que o futuro tecnológico, econômico e social deste país não se construirá à revelia do coração e da inteligência, como tantas vezes ocorreu no passado e ainda sucede no presente, mas erguer-se-á sob o signo da arte, signo sob que Brasília nasceu"' e o autor concluía contrariando a atmosfera positiva de 1959: "Brasília, entretanto, é 'aurora que não deu sol'. Decepcionou aqueles que a construíram ou que viram nela um símbolo. (...) O sonho, enfim, desfez-se antes mesmo de entrarmos na metade da nova década. O Brasil não acompanhou a revolução de Brasília, ou melhor, não assumiu sua perspectiva utópica. O futuro do país está cada vez mais sendo construído à revelia do coração e da inteligência." (MORAIS, 1975, p. 80) ${ }^{1}$.

Em 1978, Morais voltava a tratar do tema do encontro e do desencontro entre o projeto sociopolítico e o estético da construção de Brasília, ainda que o desenvolvimentismo tivesse esgotado sua perspectiva utópica o mesmo não se poderia dizer da utopia construtiva na arte e de seu potencial socialmente transformador:

"Não se pode inferir, porém, apressadamente que o fim do 'sonho desenvolvimentista' seja também o fim do 'sonho construtivo', pois se os paralelismos existem, a arte está sempre à frente da realidade. O certo é que nas décadas de 40/50 há uma coincidência de objetivos entre as ideologias construtivas no plano cultural, o desenvolvimentismo no plano econômico e as alianças continentais no plano político." (MORAIS, 2004, p. 178).

É claro que a avaliação de Morais esteve se não comprometida pelo menos prejudicada pelas condições adversas do momento vivido no País: descrença no papel revolucionário das instituições, anseio de aproximação da arte com a vida,

\footnotetext{
${ }^{1}$ Esse pronunciamento foi equivocadamente atribuído a Mário Pedrosa por Frederico Morais (MORAIS, 1975, p. 80). O referido pronunciamento foi feito pelo então Presidente da República Juscelino Kubistchek na sessão inaugural do Congresso Extraordinário da Associação Internacional de Críticos de Artes, realizada em Brasília, no dia 17 de setembro de 1959. Provavelmente o texto foi redigido por intelectual ligado ao I.S.E.B. (Instituto Superior de Estudos Brasileiros) que fez propaganda ideológica no período desenvolvimentista.
} 
incerteza com relação ao futuro a médio e longo prazo no Brasil, já que não se sabia quanto tempo a Ditadura se manteria no poder. Esses fatores conjecturais e que dizem respeito à geopolítica do momento (no Brasil e no mundo) marcaram uma nova atitude da vanguarda na arte, isto é, a descrença no projeto moderno era também a descrença no sistema e nas instituições que faziam parte disto que chamamos de moderno. O moderno assumia no Brasil sua versão conservadora identificada com a expressão "modernização conservadora"².

Pode-se dizer que, o insucesso da síntese não se devia apenas aos paralelismos, mas ao fato de o desenvolvimentismo atender interesses específicos do Capital e aquiescer com o problema da terra no Brasil. Aliás essa era uma das preocupações evidentes na de Mário Pedrosa ao dizer no Congresso promovido pela Associação Internacional de Críticos de Arte (AICA), em 1959:

\begin{abstract}
"Não tem sentido projetar uma cidade como esta num deserto como este, a mil quilômetros dos centros culturais do País, se não se fizer simultaneamente a planificação (...) para tanto é preciso entrar pelo caminho das reformas profundas no país, a começar, por exemplo, pela reforma da estrutura agrária secular." (Congresso Internacional Extraordinário de Críticos de Arte, 1959, p. 47).
\end{abstract}

Do fim das vanguardas construtivas às manifestações de arte conceitual, a crítica brasileira foi exilada de seu papel primordial na interpretação da arte e de sua significação social; os que sobreviveram e persistiram no ambiente cada vez mais mortalmente grosseiro e opressivo, sob o comando militar, tiveram de se adequar à diplomacia das meias-palavras e ao empenho involuntário e canhestro, com vantagens particulares ou não, de subordinação à nova ordem estabelecida. De toda sorte, a verve combativa da crítica politizada dos anos de 1960 é substituída

\footnotetext{
2 Termo utilizado por Celso Furtado. Para uma análise mais profunda sobre a teoria do subdesenvolvimento e a modernização conservadora, reporto o artigo de quando subdivide a obra de Furtado: "A implicação de longo prazo na adoção de modelos políticos autoritários e sua repercussão na possibilidade de construção do desenvolvimento nacional, em especial quanto aos problemas políticos e econômicos que impedem, pelo seu anacronismo, o término da energia do desenvolvimento planejado ao afastarem-se do ciclo de mudanças proporcionado pelo modelo democrático" (CEPÊDA, 2008, p. 362)
} 
progressivamente por outra, às vezes, mais impotente e servil ou, às vezes, pactuada com a ordem estabelecida no que concerne aos apaziguamentos políticos ou institucionais e que termina por fazer concessões tanto por sobrevivência como para manutenção da produção e das instituições artísticas no Brasil.

Nesse processo histórico, é possível acompanhar a mudança e a precariedade da condição de exercício da crítica brasileira. Uma atividade crítica em duas sendas, que passa de um papel ativo no ambiente cultural brasileiro dos anos de 1950 em diante para a sobrevida no início dos anos de 1970. Por uma via, a crítica exilada encontrava ressonância nas opiniões e denúncias feitas por intelectuais e artistas que aqui ainda permaneceram depois do estabelecimento do terror de direita. Esses intelectuais e artistas foram responsáveis pelas principais manifestações da vida política e cultural no decorrer dos anos de 1960 no País. É justamente a partir das iniciativas e das reflexões deles que muita coisa interessante e inovadora foi produzida no Brasil. Por outra via, entre os que ficaram por aqui, desenvolveu-se uma crítica ligada menos à realidade política do que à revolução dos comportamentos, dos costumes e do poder coercitivo e simbólico das instituições sociais.

Essas duas sendas pareciam combater o mesmo inimigo com perspectivas diversas, mas complementares, anunciando que o combate à Ditadura deveria significar a luta contra a repressão política e contra a repressão dos comportamentos; Pode-se dizer sem medo de errar que a primeira tarefa foi mais importante do que a segunda. O mote da época era libertação e liberdade; libertação das condições sociais e econômicas que nos relegavam à condição subdesenvolvida; libertação da opressão política da ditadura e do imperialismo norte-americano em favor da emancipação social em novo regime; liberdade necessária para a renovação dos comportamentos e dos costumes.

A tradição crítica estabelecida desde o início de 1950, passando pela construção de Brasília, até meados da década de 1960, representada em especial pela figura de Mário Pedrosa, tinha conseguido estabelecer um aporte direto na relação entre arte e sociedade, permitindo a mediação profícua entre a nova arte e o público. Se Brasília foi o ponto alto da realização última do projeto moderno no Brasil, toda a atividade cultural relacionada ao período desenvolvimentista ficou comprometida a partir do Golpe dos militares. Assim, a figura da crítica de arte representada, por Pedrosa, como sinônimo de interlocução entre arte e público, de 
discernimento entre produção social e artística, foi aos poucos perdendo sua importância e sendo substituída pela crítica interessada na transformação dos comportamentos (entendida como revolução, sobretudo simbólica), mas tão complacente com o mercado de arte quanto com a ocupação de espaços institucionais da arte de prestígio e legitimados pelas condições sociais préexistentes na finada era democrática e desenvolvimentista brasileira.

Se o golpe militar não provocou nenhuma reação imediata de artistas, com o decorrer da década de 1960 até a promulgação do Al-5, aconteceram pelo menos alguns eventos importantes: a mostra Opinião no Rio de Janeiro e Propostas em São Paulo, ambas de 1965 e que tiveram reedição em 1966, e logo em seguida, foi realizada a exposição Nova Objetividade, no Rio de Janeiro em abril de 1967. Em um primeiro momento, a aproximação entre arte e vida ocorreu pela chegada da onda Pop art no Brasil. Essa manifestação artística tornava-se tanto referência da ascensão dos mass media no mundo e no Brasil como sinal da equivalência entre produtos distintos para o consumo generalizado de imagens; com o passar dos anos, aconteceu a entrada cada vez mais decisiva do mercado de arte na lógica de funcionamento do sistema da arte brasileira.

Conforme diria Pedrosa em 1975, o sistema das artes fechou-se na lógica do mercado: "a mostra de arte passa a ser feira de arte, e os marchands passam a dominar. As leis do mercado capitalista não perdoam: a arte, uma vez que assume valor de câmbio, torna-se mercadoria como qualquer presunto" (PEDROSA, 1975, p. $257)^{3}$. Vários intelectuais próximos e companheiros de Mário Pedrosa, que fizeram parte do ambiente e das manifestações do projeto construtivo brasileiro tiveram o mesmo destino que ele e pressionados pela perseguição militar acabaram por se exilar no exterior, tal como foi o caso de Ferreira Gullar e de Hélio Oiticica. Este último, por não ser alvo prioritário da polícia foi responsável por ser porta-voz dos ideais e da força crítica da geração construtivista. Tanto Ferreira Gullar como Hélio Oiticica partiram das experiências construtivas para a reflexão intelectual e poética

\footnotetext{
${ }^{3}$ Assim, no Brasil, com a crise do projeto moderno e principalmente com a política militar do Al-5, a crítica de arte foi exilada ou assumiu papel inexpressivo em relação ao apoio de tendências artísticas no sistema das artes. No caso da crítica internacional, sua tarefa passou a ser decisiva quando se falava menos de seu caráter judicativo, no que concerne à síntese da estética moderna, que do novo crítico-marchand representado por Leo Castelli cujo principal objetivo era justamente a inserção de artistas no sistema das artes no padrão do Make Money (CAUQUELIN, 2005, pp. 117-125).
} 
sobre a especificidade brasileira, sobre o nacional e o popular no Brasil e sua relação com o campo internacional.

A produção poética de Hélio Oiticica revela bem a contradição entre os elementos estruturantes da realidade social brasileira e a crise da vanguarda construtiva embasada na ideia de reestruturação social a partir de princípios norteadores da arquitetura e das artes visuais no Brasil. Com o fechamento dessa perspectiva utópica comandada e principiada pela arte, a crítica de arte brasileira e os artistas se depararam com o golpe militar e a degenerescência das reformas do Estado liberalizante no sentido de garantir ampliação efetiva de direitos para as camadas sociais menos visibilizadas e favorecidas no Brasil. A geração mais nova de nossa crítica de arte e da produção artística do período - refiro-me aos anos de 1960 - laborou ao lado da antiga geração e a partir dela tomou posição frente aos problemas estéticos contemporâneos; com o passar do tempo essa geração mais jovem ocupou o vácuo deixado pelo exílio de muitos combatentes da geração construtiva.

Oiticica não foi só um dos articuladores do boicote à Bienal em 1969, mas também o idealizador e realizador de várias ações coletivas que organizaram os artistas daquele momento para formarem uma oposição unida contra o inimigo comum. Entre as ações realizadas por Oiticica estão: a participação na exposição Opinião 65, com moradores da favela Mangueira para questionar o abismo social (negros e brancos, pobres e ricos) e estético (arte e cultura dita erudita em oposição ao popular) da sociedade brasileira dividida em classes; a participação na exposição Opinião 66; a realização da instalação Tropicália como alegoria da modernização contraditória brasileira na mostra Nova Objetividade Brasileira, sendo responsável pelo Manifesto da mostra realizada no MAM do Rio de Janeiro em 1967; no ano seguinte organiza manifestação artística no aterro do Flamengo com a denominação de Apocalipopótese.

No caso de Oiticica e de muitos outros artistas, tratava-se de pensar o espaço da arte para além dos museus e dos espaços curatoriais tradicionais da arte moderna. Essa aproximação entre arte e vida fez com que a dimensão social da arte ficasse mais evidente. Ainda que Morais acentue a revolução dos comportamentos, o que se evidenciava com mais contraste era justamente a dimensão da arte na vida terceiro-mundista brasileira. Sobre as manifestações de arte na rua nos finais de semana, Morais comenta: 
"Coincidindo com as passeatas, houve um aumento de manifestações de arte-na-rua. Antes de 68 tivemos, os 'parangolés' coletivos de Oiticica, no MAM do Rio e no Aterro da Glória. Em São Paulo, em 67, a exposição de bandeiras de Nelson Leirner e Flávio Motta, impedida de continuar em praça pública, porque a fiscalização alegou falta de alvará de licença (...). A mais importante promoção nesta faixa, em 68 , foi 'um mês de arte pública', que o Diário de Notícias promoveu, em julho, no Parque do Flamengo. Durante todo o mês revezaram-se exposições de artistas de vanguarda ao ar livre (Dileny Campos, Mirian Monteiro, Ione Saldanha, Julio Plaza, Pedro Escosteguy e o grupo 'Poema-Processo'(...). Paralelamente, ainda nos fins de semana, eram promovidas manifestações, como as de Roberto Morriconi, que estourou balões e vidros contendo água colorida, com tiros de espingarda, enquanto Oiticica comandou a manifestação final, denominada 'apocalipopótese'. Esta consistiu em acontecimentos simultâneos, sem qualquer lógica explícita, senão a criação em nível de participação geral do público: 'sementes' de Ligia Pape, 'Apoliroupas', de Samir Mattar, 'As Três graças do apocalipse', de Roberto Lanari, 'Urnas Quentes', de Antonio Manoel, show de cães amestrados, sob o comando de Rogério Duarte e 'capas' de Oiticica, vestidas por passistas da Mangueira, Portela e Salgueiro. A publicidade sobre 'Arte no Aterro', eminentemente popular, foi feita na base de volantes distribuídos aos milhares, nas ruas" (MORAIS, 1975, p. 94-95).

Antes de seu exílio, Mário Pedrosa já tinha lutado em favor da mobilização de artistas e de intelectuais para boicotar a Bienal de São Paulo. Em pleno período de vigência do Al-5, a censura de obras "consideradas políticas" de artistas para a participação da IV Bienal de Paris, feita por censores militares, provocou o protesto da Associação Brasileira de Críticos de Arte (ABCA) na figura de Pedrosa e levou ao boicote em massa feito por artistas internacionais à Bienal de São Paulo de 1969. O clímax do agravamento de sua relação com o governo militar foi o episódio de sua viagem de estudo patrocinada pela UNESCO; Pedrosa foi responsabilizado pelo governo militar de ter enviado carta-denúncia contra a tortura para a UNESCO, o que foi considerado pelos militares um modo de denegrir a imagem do Brasil no exterior, mas inquirido pela investigação policial, se solidarizou com os presos e torturados, o que Ihe valeu imediatamente um indiciamento. Em julho de 1970, 
Pedrosa tem sua prisão decretada e inicia sua fuga para o Chile e a participação breve e enquanto durou a experiência socialista no governo de Salvador Allende no Chile. Esse foi o período do grande êxodo de artistas, intelectuais e militantes brasileiros, que por força das circunstâncias, são obrigados a deixar o Brasil.

Mas afinal, o que podia se conceituar como vanguarda no Brasil dos anos pós-Ditadura e de recrudescimento do terror militar? Não havia, por assim dizer, um anacronismo no uso do termo, quando se constata que já se tinha avançado para uma nova rotina da arte, que foi denominada por Mário Pedrosa de arte pósmoderna? O termo vanguarda passou a ser usado nos fins de 1960 e início de 1970 como referência direta ao experimentalismo da arte brasileira em oposição à tradição nacional-popular representada pela arte política ou engajada que dando ênfase ao conteúdo em detrimento da forma, na suposição mecânica da separação desses termos, fazia do didatismo artístico uma tentativa de aproximação com as massas em busca da valorização do elemento nacional inscrito nas diversas manifestações da cultura popular brasileira. Esses elementos de afirmação dos valores da cultura popular brasileira seriam posteriormente aclimatados e incorporados pela propaganda e pelo discurso ideológico da Ditadura Militar.

$\mathrm{Na}$ política, ainda que as decisões da Ditadura estivessem atreladas aos interesses norte-americanos para o Continente, o que consolidou principalmente, a partir dos anos de 1970, o interesse pela primazia ideológica do mercado na arte, intelectuais e artistas brasileiros andaram na contramão dessa tendência oficializada no Brasil. Devemos lembrar que nos de 1960, ocorre uma série de eventos no mundo que mudariam os sentidos tradicionais da política e dos comportamentos. Nesse período, destaca-se o maio de 1968 na França e a campanha contra a guerra do Vietnã nos Estados Unidos; ambos os eventos ganharam irradiação para além das próprias fronteiras nacionais. No caso da revolução de Maio de 1968 marcou decisivamente o ensino superior tanto nas universidades francesas e europeias e como no mundo. A politização dos estudantes, que passaram a exercer papel central na formulação e na condução das principais atividades contraculturais no período, foi resultado em parte do processo que nos anos anteriores tinha levado, pelo menos na França, à incorporação de uma gama maior de jovens pertencentes a 
um amplo espectro social, a uma gama maior de indivíduos de classes sociais distintas dentro da universidade ${ }^{4}$.

A aposta Frederico de Morais em uma arte que superasse os limites do espaço tradicional do sistema das artes realizara-se aos poucos a partir de uma série de experiências que já estavam presentes nas experimentações neoconcretas e nas propostas de Hélio Oiticica, nas manifestações artísticas do Grupo Rex ou do próprio Nelson Leirner.

Quando Morais organizou eventos no Aterro do Flamengo a proposta já era, como em Oiticica, de eliminar a distância entre a arte contemporânea, seu significado social e as camadas populares. Aproximar as pessoas da arte, aproximar a arte da vida, esse foi um dos objetivos dos eventos que marcaram a démarche experimental dos anos de 1960 e de 1970. No caso específico das artes, o objeto (como categoria artística) tinha ganhado importância no processo de comunicação das linguagens visuais e tornou-se elemento chave para a realização da exposição Objeto e Participação no Palácio das Artes em 17 de abril de 1970. Juntamente com a exposição, Morais pensou na realização de manifestações artísticas (arte vivencial, conceitual e efêmera ou etc.) no espaço do Parque Municipal de Belo Horizonte, conhecida como Do corpo à terra, entre os dias 17 e 21 de abril de 1970.

As manifestações artísticas Do corpo à terra envolviam uma nova concepção de arte, ligada à efemeridade, às vivencias e à abertura do processo de significação

\footnotetext{
${ }^{4}$ Os antecedentes de maio de 1968 são a recessão e o desemprego que atingira operários franceses e que acrescida da falta de horizontes promissores no futuro imediato produzia um efeito psicológico negativo entre os jovens universitários. Isso fica evidente quando se constata que as primeiras manifestações políticas e os antecedentes da rebelião dos jovens começaram nas universidades do interior da França em cursos de Letras e de Humanidades. Essas rebeliões foram iniciadas justamente por jovens que tinham consciência da contradição entre a formação humanística que recebiam e o posto de trabalho que ocupariam depois de formados, contradição entre a formação muito inferior exigida pelos postos de trabalho e aquela recebida na Universidade, e a constatação de que muitos deles não escapariam ao desemprego. (MATOS, 1989, pp. 20-21). No mundo e em particular no caso da França, o pós-guerra foi marcado pelo desenvolvimento inexorável de aparelhos estatais e privados que aprofundaram a dinâmica e as práticas do gerenciamento das sociedades modernas segundo as normas de racionalização ou engenharia social e produtivismo econômico: "Estudantes franceses, os de Berlim ou de Berkeley entraram em conflito contra os aparelhos de integração, manipulação e agressão. (...) o conflito começou sendo cultural e político, antes de ser econômico. Não é por acaso que a ciência é questionada, tal como se lê em um panfleto distribuído em Paris em maio de 1968: 'recusemos também a divisão da ciência e da ideologia, a mais perniciosa de todas, que é secretada por nós mesmos. Não queremos mais ser governados passivamente pelas leis da ciência como também pelas leis da economia ou os imperativos da técnica. Recusemos o imperialismo mistificador da ciência, caução de todos os abusos e recuos (...) para substituí-la pela escolha real entre os possíveis que ela nos oferece'. Quer dizer: para que a ciência e a técnica sejam liberadoras, é preciso que se modifiquem sua orientação e seus objetivos atuais de produção dos meios de destruição sociais. O maio francês pôs por terra a crença na ideia de progresso (e podia-se ler nos muros de Paris): 'nosso modernismo não passa de uma modernização da polícia"' (MATOS, 1989, pp. 24-25).
} 
em que o público e a arte estavam em um campo aberto para experiências possíveis, mas não obrigatórias. Essa abertura levava se não à abdicação do curador em vivenciar e presenciar todo o evento pelo menos de submetê-lo a outro crivo, o crivo do conceitual e do anteriormente projetado. Afinal tanto público como curador foram testemunhas de parte apenas dos eventos; essa impressão de fragmentariedade da experiência do evento andou pari passu com a abertura de possibilidades de experimentar ou não o tensionamento entre arte e público. Diz Morais:

"Foram vários os aspectos inovadores em ambos os eventos, a saber: 1 pela primeira vez, no Brasil, artistas eram convidados não para expor obras concluídas, mas para criar seus trabalhos diretamente no local e, para tanto, receberam passagem e hospedagem $\mathrm{e}$, juntamente com os artistas mineiros, uma ajuda de custo; 2- se no Palácio houve um vernissage com hora marcada, no Parque os trabalhos se desenvolveram em locais e horários diferentes, o que significa dizer que ninguém, inclusive os artistas e o curador, presenciou a totalidade das manifestações individuais; 3- os trabalhos realizados no Parque permaneceram lá até sua destruição, acentuando o caráter efêmero das propostas; 4- a divulgação foi feita por meio de volantes, distribuídos nas ruas e avenidas de Belo Horizonte, bem como nos cinemas, teatros e estádios de futebol, tal como já ocorrera com Arte no Aterro." (MORAIS, 2004, p. 117).

Na época Morais escreveu um Manifesto que dava dimensão à atitude dos artistas frente ao estado de coisas produzido pela Ditadura:

"Somos bárbaros de uma nova raça. Os imperadores da velha ordem que se guardem. Nosso material não é acrílico bem comportado, tampouco almejamos as estruturas primárias higiênicas. O que fazemos são celebrações, rituais sacrificiatórios. Nosso instrumento é o próprio corpo contra os computadores. Nosso artesanato é mental. Usamos a cabeça contra o coração. Ao invés de 'lasers' - imaginação. E as vísceras e o esperma se necessário. O sangue e o fogo purificam. Nosso problema é ético - contra o onanismo estético. (...) Vanguarda não é atualização de materiais, não é arte tecnológica e coisas tais. É um comportamento, um modo de ser e de encarar as coisas, os homens e os materiais, é uma atitude definida diante do mundo." (MORAIS, 1975, pp. 94-95). 
É preciso lembrar que a Bienal de outubro de 1969 foi boicotada por artistas e intelectuais brasileiros e estrangeiros. Quando Frederico Morais fala da relação entre arte e tecnologia, da arte tecnológica do início dos anos de 1970, provavelmente ele está se referindo à atividade paralela da Bienal que foi a II Bienal de Ciência e Humanismo, que teve a participação de teóricos e gente ligada ao mundo acadêmico. Nomes tais como Isaac Epstein, Vilém Flusser e tantos outros constam nos anais do congresso.

Digressões à parte, a negatividade propositiva da arte pós-moderna segundo definição de Mário Pedrosa (2004) - geraria uma arte que conseguiu vingar em momento muito adverso no Brasil, em solo árido de tempos difíceis. Hoje se sabe que grande parte das principais manifestações de radicalidade inovadora da arte brasileira surgiu nesse período de ebulição política, social e artística. Hoje se sabe também que enquanto a vanguarda brasileira apontava para os horizontes da transformação social plena do País, o que veio a seguir foi uma resposta denunciadora da situação política e de poder no país; com o passar do tempo, o sistema de arte brasileiro rumou para o adesismo cada vez mais tacanho à lógica de mercado.

Alguns anos depois Do corpo à terra em 1970 e dos encontros denominados Domingos da Criação em 1971, Frederico Morais fez um balanço da arte do lugar da vanguarda no Brasil desde os anos de 1950 até o golpe militar e posteriormente à edição do Al-5. Morais considerou as manifestações Do corpo à terra como conclusivas da atividade da Vanguarda no Brasil. No ensaio A crise da vanguarda no Brasil, Frederico Morais assume esquema propositivo em que a atitude contra a cultura vigente e suas instituições e, principalmente, contra a arte estabelecida em forma de antiarte marcou o compromisso propositivo da vanguarda brasileira da segunda metade da década de 1960 e durante a década seguinte. De um lado, a vanguarda era negatividade propositiva e, de outro, negação de possibilidades, crise de paradigma. Dessa dualidade tem-se a crise da vanguarda entendida como crise do moderno e proposição de negação dos paradigmas estabelecidos pelo moderno para transcendê-los em um novo status para a arte e para a vida: 


\begin{abstract}
"A contra-arte soma a contestação política à contestação da própria arte (sobretudo suas categorias tradicionais). Os novos artistas desta tendência têm em Oiticica e em Lygia Clark, ambos vivendo no exterior, seus modelos, mas sua arte é cada vez mais conceitual. O que fazem são rituais, celebrações, exercícios perceptivos, tensionamento dos sentidos, expedições, apropriações, trabalhos ecológicos. Surgidos repentinamente, vindos de outros setores, fazem uma arte selvagem, que tende ao nomadismo (fora dos museus e galerias, de preferência) e ao anonimato. Atuam imprevistamente, como guerrilheiros, sem anunciar, e onde menos se espera." (MORAIS, 1975, pp. 103-104).
\end{abstract}

Essa era a nova face da antiarte no Brasil. Uma antiarte que negava não somente a velha moral e os costumes burgueses de sua época (não se tratava apenas de uma revolução de comportamentos), mas que envolvia a ligação desses artistas com a agudização da crise política e social vivida no País. Nesse momento, os artistas seguem o exemplo dos guerrilheiros e imergem na vida, fazem das táticas e do imprevisto, grandes trunfos para se posicionarem contra o estado de coisas existente. As trouxas de sangue de Arthur Barrio, ar urnas de Antonio Manuel, as galinhas queimadas vivas de Cildo Meireles e, logo depois, a confecção de coquetéis molotov com garrafas de Coca-Cola não deixam margem a qualquer dúvida sobre a aproximação dos artistas com os movimentos da ampla gama da esquerda resistência política no Brasil nos idos de 1970.

Todos os acontecimentos artísticos curados por Morais no período (19681975) levaram em conta a efemeridade das propostas não menos pela aproximação entre arte e vida que pela adesão às práticas muita vez individuais potencialmente transformadoras da ordem estabelecida. Morais defendia a crítica de arte como atividade criativa (por extensão podemos entender a posição do curador) em que o crítico ou o curador ocupavam-se com a criatividade, com a produção de experiências artísticas. É nesse sentido que Morais concebe os Domingos da Criação. Se Morais parece ceder ao otimismo das transformações comportamentais produzidas pela arte no contexto da participação estética e social em tempos de Ditadura, a produção artística ou as intervenções dos artistas situavam-se para além do campo exclusivamente ético ou moralizante. Daí a força de proposições políticas assumidas pela arte conceitual no Brasil. 
O grande inimigo dos artistas parecia ser, como ressaltou Carlos Zílio, a Ditadura e com as ingerências do imperialismo norte-americano, de onde mais uma vez ressurge o tema do nacional e da brasilidade, de forma negativa, para reorientar o debate sobre artes visuais, cultura e política no Brasil. O que se queria agora era justamente trazer o tema do debate sobre o nacional e a brasilidade no sentido de afastar as ameaças de fetichização dos ícones nacionais que se transformariam em símbolos-instrumentos da ideologia nacionalista construída pela Ditadura: a seleção de futebol campeã, o ícone brasileiro Pelé, a primeira transmissão da Copa do Mundo pela TV em cores. Frederico Morais termina seu ensaio com visão conformista e até certo ponto basbaque com relação ao estabelecimento do mercado de arte brasileiro embora identificando a desestruturação geral de nosso sistema das artes. 